\title{
Caracterização da produção de tomate-industrial no município de Morrinhos/GO: da utilização de defensivos à vantagem dos contratos
}

\author{
Paulo Eterno Venâncio Assunção* \\ Eiko Mori Andrade Spinelli** \\ Jordão Silva Cardoso*****
}

\section{Resumo}

O presente trabalho procurou caracterizar os produtores de tomate da região do município de Morrinhos/GO, examinando os custos de produção e destacando o impacto do uso de defensivos no custo de produção, bem como a rentabilidade da atividade. Também buscou analisar a importância dos contratos agrícolas para os produtores e as indústrias processadoras da produção de tomate no município selecionado. Os dados obtidos foram submetidos à análise proposta por Samuelson e Nordhaus (1993), para que fosse feito o cálculo das receitas. O teste $t$ de Student foi utilizado para comparação das médias dos custos de produção e da receita líquida dos produtores nos dois grupos, grandes e pequenos produtores. Posteriormente, foi utilizado o modelo de receita líquida proposto por Hoffmann (1998), que se baseia em um logaritmo para determinar a receita líquida obtida em determinado negócio. Notou-se que os produtores abusam do uso de defensivos agrícolas, aumentando seus custos de produção, e que os contratos apresentam vantagens para a defesa do produtor, garantindo lucros, e para a indústria, garantindo produtos de maior qualidade.

Palavras-chave: Morrinhos/GO. Contratos. Defensivos. Tomate.

* Engenheiro Agrônomo, Mestrando do Programa de Pós-Graduação em Agronegócio da Universidade Federal de Goiás e Estagiário de Pós-Graduação em Socioeconomia da Embrapa Arroz e Feijão. paulo_eterno05@hotmail.com.

** $\quad$ Mestre em Fitopatologia, Professora e Coordenadora do Curso de Agronomia da Faculdade de Filosofia e Ciências Humanas de Goiatuba. eikomori@yahoo.com.br.

**** Estudante de curso de Engenharia Agronômica da Faculdade de Filosofia e Ciências Humanas de Goiatuba. E-mail.

http://dx.doi.org/10.5335/rtee.v0i40.3448

Submissão: 27/11/2012. Aceite: 21/06/2013 


\section{Introdução}

O tomate, uma das hortaliças mais consumidas no Brasil, figura entre as mais plantadas, sendo considerada pelos nutricionistas um dos frutos mais completos para consumo humano. $\mathrm{O}$ tomate de mesa é a terceira hortaliça com maior volume de produção no Brasil. São comercializadas, anualmente, cerca de 1,5 milhões de toneladas dentro do país (EMBRAPA, 2011).

A tomaticultura brasileira coloca o país entre os maiores produtores de tomate do mundo. Em 2011, a área plantada foi de 71 mil hectares, 5\% maior do que a plantada em 2010, que foi de 68 mil hectares. Houve um aumento, também, em relação à quantidade de tomate produzida: em 2010 , a produção foi de 4,1 milhões de toneladas, já em 2011, foi de 4,4 milhões, perfazendo um aumento de 8\% (IBGE, 2013).

Goiás é detentora da maior área plantada de tomate no país, com 18 mil hectares ocupados com a cultura em 2011 e com uma produção, no mesmo ano, de 1,4 milhões de toneladas, colocando o estado como o maior produtor do fruto no Brasil (IBGE, 2013). Cerca de 67\% do tomate produzido dentro do estado segue para o processamento industrial, demonstrando a força desse segmento dentro do contexto goiano (CARVALHO; PAGLIUCA, 2007).

A cadeia agroindustrial do tomate tem destaque entre as mais importantes no cenário do agronegócio nacional. A montante do setor produtivo, a cultura do tomate para processamento industrial movimenta as indústrias paralelas de insumos, embalagens, máquinas agrícolas e equipamentos de irrigação (MELO; VILELA, 2004).

Desde 1990, a cultura vem se expandindo na região Centro-Oeste, onde a baixa umidade relativa do ar e as temperaturas amenas, entre os meses de março e setembro, favorecem o cultivo do tomateiro (EMBRAPA, 1994). Os solos profundos, bem drenados e a topografia plana existente nas áreas de produção desses estados facilitam a mecanização e permitem o uso de grandes sistemas de irrigação (EMBRAPA, 1994). A agroindústria brasileira tem capacidade instalada para processar 22.089 toneladas diárias, em 35 unidades processadoras, distribuídas nos estados do Ceará, de Pernambuco, da Bahia, de Goiás, Minas Gerais e São Paulo (EMBRAPA, 2011).

A cultura do tomate industrial é altamente sensível às pragas e doenças, exigindo uso intensivo de defensivos químicos, que oferecem grandes riscos de contaminação aos trabalhadores, consumidores e ao ambiente em geral, além de constituírem num fator importante na formação dos custos variáveis da produção dessa

Teoria e Evidência Econômica - Ano 19, n. 40, p. 153-168, jan./jun. 2013 
cultura (SILVA et al., 1998). O presente trabalho faz-se importante para diagnosticar como é feita a produção de tomate na região de Morrinhos, quanto aos aspectos culturais, produção e relação dos produtores com a indústria processadora.

Diante dos aspectos apresentados, o presente trabalho buscou analisar os custos de produção, destacando o impacto do uso de defensivos nesse tocante, bem como a rentabilidade da atividade. Também teve como objetivo investigar a importância dos contratos agrícolas para os produtores e as indústrias processadoras da produção de tomate na cidade de Morrinhos.

\section{Referencial teórico}

\subsection{Contratos}

A coordenação do agronegócio tem sido um tema muito debatido, em razão da grande variedade de arranjos institucionais que vem surgindo em diversas economias e sistemas (ROCHA JÚNIOR, 2008). Nogueira (2003) destaca que os arranjos - como os contratos de fornecimento de longo prazo, subcontratação (terceirização) de fornecedores de produtos e serviços, condomínios industriais, modalidade em que os fornecedores operam nas instalações do próprio cliente, contratos de franquia, contratos de exclusividade de canal, entre outros modos - são estruturas de governança que vêm se estabelecendo com grande frequência na atualidade.

Em relação ao agronegócio, Rocha Júnior et al. (2008) evidenciam que a análise da coordenação de sistemas agroindustriais faz-se necessária em virtude das tendências apresentadas nas últimas décadas de estreitamento dos relacionamentos e das negociações entre as mais diversas etapas de transformação e consumo. A coordenação, ao longo de sistemas agroindustriais, utiliza-se de vários mecanismos de estrutura de governança, incluindo mercados (preços), contratos implícitos e alianças, contratos formais, joint-ventures e integração vertical (FARINA et al., 1997). De acordo com essa perspectiva, o sistema agroindustrial deixa de ser tratado como uma série de transposições de relações tecnológicas e passa a ser abordado como um nexo de contratos, como proposto por Coase (1993), seguindo estas proposições: a) uma cadeia de suprimento pode ser encarada como um nexo de contratos ampliado, cuja arquitetura resulta de seu alinhamento com características das transações e do ambiente institucional; b) existem arranjos contratuais que reproduzem a arquitetura contratual existente na firma, em que a motivação para a elaboração de um subsistema por algum agente dentro da cadeia parte das 
estratégias de mercado e da busca de eficiência em custos de transação, podendo gerar contratos informais.

Conforme Zylbersztajn (2005), a complexidade, tanto quantitativa como qualitativa, das atividades dos agentes participantes dos sistemas agroindustriais determina as condições de se estabelecerem relações contratuais formais ou não entre esses agentes. $\mathrm{O}$ autor ainda destaca que os contratos são uma maneira de coordenação das transações, conduzindo a promoção de incentivos para que os agentes atuem de maneira coordenada no momento da produção, de modo a permitir um planejamento de longo prazo de ambas as partes.

Os contratos envolvem custos relacionados à sua construção, implementação, ao seu monitoramento e à solução de disputas advindas do seu não cumprimento. As instituições e organizações, por sua vez, são estruturadas para atuar diante dessas disputas, desenvolvendo, ainda, tribunais informais e de justiça (ZYLBERSZTAJN; SZTAJN, 2005).

Segundo Fiani (2002), pode-se destacar quatro tipos de contratos:

- contratos que caracterizam no presente certo desempenho no futuro; não são flexíveis, indicados apenas para transações simples, em que a incerteza e a complexidade não estejam incluídas;

- contratos que especificam no presente determinado desempenho futuro, com cláusulas condicionais; indicados quando há interesse em manter um vínculo entre vendedor e comprador, devido ao fato de os ativos possuírem alta especificidade; quanto maior a complexidade da transação, mais difícil elaborar esse contrato; a racionalidade limitada impede a antecipação de todas as circunstâncias futuras;

- contratos de curta duração, indicados apenas quando há necessidade de realizar a transação; as ofertas são feitas em mercado spot (à vista) e cada comprador adquire o que deseja e quando lhe convém; o objetivo da transação deve ser homogêneo, não importando quem seja o vendedor ou o comprador;

- contratos estabelecidos hoje dando direito de selecionar, futuramente, uma performance específica em um conjunto de performances estipulado anteriormente; chamado, ainda, de relação de autoridade; não é necessário antecipar todas as circunstâncias futuras nem recontratar sucessivamente; referem-se, principalmente, aos contratos de trabalho de longa duração.

No âmbito do agronegócio, os contratos ocorrem entre várias partes, tais como fornecedores de insumos, supermercados, distribuidores, agroindústrias e outros, e, por serem relações que ocorrem com frequência, não lhe se atribui a importância necessária (PEREIRA et al., 2008). 
Os agricultores organizam-se horizontalmente (coordenação horizontal), em especial de forma cooperativa, visando a ganhos econômicos de escala, de rede, a ampliar a capacidade de coordenação com as indústrias processadoras, bem como a adicionar valor de forma seletiva (ZYLBERSZTAJN, 2005). Na coordenação vertical, os contratos correspondem a uma parcela significativa na produção rural (MIELE, 2006). A adoção dos contratos deve-se, em parte, à redução de riscos aos produtores, que não precisam negociar no mercado, reduzindo, assim, os custos de transação, os quais são os mais significativos às organizações (PEREIRA et al., 2008).

A agricultura contratual tem sido vista como uma possível ferramenta de incremento rural dos países em desenvolvimento. É um sistema estratégico que visa a resolver a crise agrária desses países, como um mecanismo de incrementar a segurança alimentar, como uma ferramenta do desenvolvimento regional e, por último, como base dos programas de assentamento de terras (DIAS, 2000).

\subsection{Custos de produção}

A utilização de estimativas de custos de produção na administração de empresas agrícolas é de grande importância tanto na análise da eficiência da produção de determinada atividade, quanto na análise de processos específicos de produção, os quais indicam o sucesso de determinada empresa no seu esforço de produzir (MARTIN et al., 1994). A agricultura tem se tornado cada vez mais competitiva, e com o crescente processo de diminuição da intervenção governamental no setor, o custo de produção transforma-se num relevante instrumento no processo de decisão.

De acordo com Calderón e Ferreira (2004), uma das formas de determinar a viabilidade econômica de um sistema de produção no curto prazo (ao longo de um ciclo produtivo) é analisar os custos e as receitas nele gerados, estudando-se o comportamento da produção e os insumos utilizados para tal.

Como refere Sraffa (1989), existe um princípio econômico segundo o qual a produtividade de uma atividade pode ser dividida em três classes: 1) uma primeira classe em que a produção (quantidade) pode ser maior do que a atual, com um incremento proporcional do custo; 2) uma segunda classe em que a produção pode ser incrementada com um aumento menos que proporcional nos custos; e 3) uma terceira classe constituída por uma produção maior, sendo obtida com um aumento mais que proporcional aos custos. Calderón e Ferreira (2004) ressaltam que a produção poderá ser incrementada com custos unitários constantes, decrescentes ou crescentes, respectivamente.

Teoria e Evidência Econômica - Ano 19, n. 40, p. 153-168, jan./jun. 2013 
Os custos podem ser demonstrados de maneiras diferentes, dependendo de sua natureza, identificação ou variação. Conforme Jiambalva (2002), são fixos os que não variam de acordo com a produção e se mantêm constantes, independentemente da quantidade produzida. O mesmo autor menciona, ainda, que os custos fixos não se alteram em resposta a mudanças nos níveis de atividade.

Mensurar os custos de produção nas propriedades rurais é uma atividade importante, pois define quanto de capital será investido em uma atividade e quanto essa atividade está dando de retorno. Belulke e Bertó (2004) evidenciam que a elaboração ou o levantamento dos custos de produção de uma propriedade rural varia de uma para outra, em extrema dependência das atividades que cada qual desenvolve e das peculiaridades produtivas que apresentam.

\section{Metodologia}

A análise realizada no presente trabalho pode ser considerada descritiva e documental. O método descritivo é aplicado quando o objetivo primordial consiste na descrição das características de determinada população, fenômeno ou estabelecimento de relações entre variáveis (GIL, 2000). A análise documental, de acordo com Marconi e Lakatos (1999), usa relatórios, atas e outros documentos que estão na forma bruta e sofrerão alguma análise específica.

Barros e Lehfeld (2000), por sua vez, enfatizam que a pesquisa descritiva tem a intenção de delinear ou de analisar as características de fatos ou de fenômenos, utilizando métodos de coleta de informações (como pesquisas em contratos específicos), a fim de reunir dados para verificação de hipóteses.

O presente trabalho foi desenvolvido com base em dois questionários aplicados a produtores de diferentes níveis na região produtora de tomate do entorno da cidade de Morrinhos/GO e em três indústrias responsáveis pelo beneficiamento dessa produção, no período de janeiro de 2010 a janeiro de 2011 . A execução do trabalho deu-se em duas etapas: uma primeira visita, para aplicação do questionário e identificação dos principais defensivos utilizados, e uma segunda visita, para recolhimento do questionário e caracterização de alguns aspectos da produção.

Fez-se uma primeira visita aos produtores, a fim de propor a aplicação do questionário e proceder ao acompanhamento de alguns tratos culturais, como a identificação dos defensivos utilizados pelos produtores, os cuidados tomados no momento da aplicação desses defensivos, sua produção, produtividade e os canais de comercialização do tomate produzido. 
Dos 25 produtores visitados, apenas quatro não aceitaram participar do projeto. Foram coletados, também, dados sobre possíveis problemas de ordem ambiental e de saúde das pessoas que trabalham com essa cultura, além de registrar-se a caracterização do produtor, de sua família e da propriedade, observando a importância que o contrato tem no que se refere à segurança da produção. Os dados fornecidos pelos produtores basearam-se em suas anotações e em notas de compras dos insumos e materiais de consumo.

Por parte da indústria, o questionário teve ampla aceitação, tendo as três aceitado participar do trabalho. Em duas, as visitas aconteceram em dois momentos e, na terceira empresa, o questionário foi aplicado via e-mail, ocorrendo uma visita posterior à sua aplicação.

Os produtores foram agrupados em grandes e pequenos. Entre os grandes, ficaram aqueles que plantaram em terras alugadas, compraram sementes de tomate longa vida, pagaram para fazer as mudas, com mão de obra assalariada e de meeiros. O grupo dos pequenos produtores foi composto por aqueles que plantaram em terras próprias e compraram prontas as mudas de tomate, empregando mão de obra marcada pela parceria, em sistema de meia e familiar, que envolve o proprietário da cultura, filhos e parentes. Quanto ao tamanho, os grandes produtores foram aqueles que plantaram acima de 50 mil pés de tomate e os pequenos, os que plantaram até esse limite.

Os dados foram submetidos à análise proposta por Samuelson e Nordhaus ${ }^{1}$ (1993), para que fosse feito o cálculo das receitas. O teste $t$ de Student foi utilizado para comparação das médias dos custos de produção e da receita líquida dos produtores nos dois grupos e entre os grandes e pequenos produtores, bem como da produtividade, a fim de se analisar quais têm renda melhor e se há mesmo essa diferenciação de renda conforme o tamanho do produtor.

Foi utilizado o modelo de receita líquida proposto por Hoffmann (1998), que se baseia em um logaritmo para determinar a receita líquida obtida em determinado negócio. As variáveis independentes foram aplicadas de acordo com o modelo, incluindo produtividade e preço, como dispostos a seguir:

$\log Y=\log K+b 1 \log X 1+\ldots . .+b 5 \log X 5+b 6 \log X 6+\log 0$, onde:

$Y=$ receita líquida (variável dependente);

$K=$ intercepto da função;

$b 1, b 2 \ldots b 5=$ coeficientes de regressão;

$X 1 \ldots X 6$ = variáveis independentes;

$0=$ erro aleatório que, se assume, tem distribuição normal. 
O modelo de regressão foi ajustado aos dados, efetuando o método dos quadrados mínimos ordinários. Para testar o nível de significância dos modelos de regressão, foi utilizado o teste "F", a 1 e a $5 \%$ de probabilidade. O teste $t$ de Student foi significativo a 1 e a $5 \%$, e os dados foram rodados no Programa Estatístico R, versão 2.14.7.

\section{Resultados e discussão}

\subsection{Caracterização dos produtores e da produção}

As 21 propriedades produtoras de tomate ocuparam 280 trabalhadores nas atividades de plantio, tratos culturais e colheita. O nível de educação e formação dos produtores pode ser considerado médio, pois todos são alfabetizados. Dos tomaticultores nessa região, 20\% possuem o ensino fundamental incompleto, 30\%, o ensino fundamental completo, $10 \%$, o ensino médio incompleto, $25 \%$, o ensino médio completo e $15 \%$, o ensino superior.

No que tange aos tratos culturais, os produtores afirmaram ter total consciência quanto aos perigos que os defensivos oferecem. No entanto, em apenas $15 \%$ das propriedades foi constatada a utilização correta de equipamento de proteção individual (EPI), tendo essa porcentagem ficado restrita às áreas de produção cujos proprietários têm curso superior. Como argumentos para não utilizá-los, os produtores mencionaram que os EPIs causam desconforto e limitam a mobilidade nas atividades, sendo, também, muito quentes. Vicente et al. (1998) e Santos e Noronha (2001), em trabalhos desenvolvidos em outras regiões de produção de tomate, constataram, igualmente, que os produtores não utilizaram EPI, alegando desconforto e retirada de mobilidade nas atividades exigidas para aplicação dos defensivos.

No período em que foram acompanhadas as aplicações, o que compreendeu uma safra, os produtores utilizaram dezoito defensivos diferentes, em aplicações sucessivas ou espaçadas por poucos dias. Esses produtos, segundo Andrei (1996), oito pertencentes à classe I (altamente perigoso), quatro à classe II (muito perigoso), quatro à classe III (perigosos) e dois à classe IV (pouco perigosos), são altamente prejudiciais à saúde humana e ao ambiente.

Das embalagens vazias de defensivos agrícolas utilizados nas pulverizações, $100 \%$ foram recicladas, pois Morrinhos conta com uma política eficiente nessa área, graças à existência de uma recicladora especializada no trabalho com esses materiais, que cobre toda a região produtora do entorno da cidade. No período 
acompanhado, os tomaticultores pulverizaram suas lavouras, em média, três vezes por semana, com alternância dos produtos utilizados.

$\mathrm{Na}$ safra acompanhada no presente estudo, apenas quatro tomatais foram atacados por doenças de ordem fúngica e bacteriana, causando uma queda de $25 \%$ na produção. As doenças que mais ocorreram foram Alternaria solani, Erwinia spp e Verticillium dahliae. Mosca-branca (Bemisia argentifolii) e a traça-do-tomateiro (Tuta absoluta) atacaram dois tomatais, provocando uma queda de $10 \%$ na produção. Nos ataques de insetos, o fruto pode ficar impróprio para envio à indústria, de modo que uma cláusula é mantida para o caso de esse problema ser observado nas propriedades, discussão a ser feita mais adiante.

Os tomaticultores receberam assistência técnica dos engenheiros agrônomos das casas onde compraram seus insumos, da Agência Rural e das empresas que produziram as mudas de tomate. Alguns grandes produtores tiveram, ainda, a assistência de engenheiros agrônomos contratados por conta própria.

O financiamento para a produção de tomate nessa região foi feito nas empresas de insumos, seguindo uma lógica que fugiu ao que se esperava. Estimava-se que o financiamento da produção fosse feito por parte da indústria, o que, porém, não ocorreu. Segundo os produtores, o crédito conseguido com as empresas de insumos é rápido, sem burocracia, e o acerto é feito logo após a venda da safra.

A média das taxas de juros foi de $2,30 \%$ ao mês para os grandes produtores e de $3,22 \%$ ao mês para os pequenos. A produtividade média encontrada foi de 172 caixas/mil pés ou $57 \mathrm{t} /$ ha. Não foram observadas diferenças estatísticas significativas entre os dois grupos de produtores. A produtividade foi igual entre os grandes e os pequenos, o custo médio de produção foi de $R \$ 12,00$ a caixa e o preço médio da caixa de tomate recebido pelos produtores foi de $\mathrm{R} \$ 13,78$.

$\mathrm{Na}$ safra observada, somados todos os produtores, foram gastos $\mathrm{R} \$ 647.234,78$ com defensivos agrícolas, $R \$ 378.789,00$ com fertilizantes, $R \$ 501.500,00$ com mão de obra e $\mathrm{R} \$ 118.578,02$ com juros de financiamento para as empresas de insumos. A receita total desses tomaticultores na região de Morrinhos/GO foi de $\mathrm{R} \$$ 3.000.678,00 numa área de 109 ha.

A equação resultante do modelo proposto, conforme entregue pelo programa estatístico $\mathrm{R}$, foi a seguinte: $\log \mathrm{Y}=\log 100+14 \log \mathrm{X} 2-8,4 \log \mathrm{X} 3-5,6 \log \mathrm{X} 4$, onde $\mathrm{Y}$ é a receita líquida, 100 é a média básica da receita, representando a receita obtida pelos produtores, X2 refere-se à variável fertilizante - considerando-se que quanto mais fertilizante adicionado, maior tendência ao ganho e que o ótimo, quando alcançado, tende à regressão na produção -, X3 são os defensivos utilizados - lembrando que quanto mais defensivos utilizados, maior a tendência em perdas 
na receita - e X4 refere-se à mão de obra - que quanto mais for empregada, mais compromete a receita. $\mathrm{O}$ valor $\mathrm{P}$, em que a probabilidade adotada era de $5 \%$, foi de $3,8 \%$, indicando que o resultado concorda com a hipótese de $\mathrm{H} 0$, onde, quanto mais das variáveis é empregado, mais se aumenta o custo.

O coeficiente de determinação múltipla apresentou o valor de 0,856 , assinalando que $85,6 \%$ das variações da receita bruta foram explicadas pelas variáveis independentes incluídas no modelo. O valor do teste " $\mathrm{F}$ " foi de 14,89 e do teste "t", de 8,7 , estatisticamente significativo ao nível de $1 \%$, indicando uma alta relação entre a variável dependente e as variáveis independentes analisadas no modelo utilizado neste trabalho.

O coeficiente da variável fertilizantes foi estatisticamente significativo ao nível de 1\%, apontando que um aumento do uso de fertilizante resulta em ganhos na receita bruta dos produtores, mas, se adicionado além do ótimo de produção, pode gerar queda na produtividade. A variável mão de obra foi significativa ao nível de $0,8 \%$ de probabilidade, no modelo da receita bruta, mostrando que um aumento nos gastos dessa variável aumentou o valor da receita bruta dos produtores.

O coeficiente de regressão da variável defensivos agrícolas não foi significativo a $5 \%$, indicando que os tomaticultores estudados utilizaram quantidades inadequadas desses produtos para que pudessem ser competitivos em relação ao mercado. Os coeficientes das variáveis depreciação e outros gastos (despesas com materiais de consumo, juros, seguros, comercialização, preparo de solo, aluguel, transporte e outras despesas) também não foram significativos, indicando não haver uma relação direta entre essas variáveis e a receita bruta dos produtores.

\subsection{Os contratos}

Foi possível fazer a caracterização dos produtores e saber em que medida os contratos os beneficiam, para que tenham segurança quanto ao escoamento e aos mercados que seus frutos terão no futuro. Dos 21 produtores que participaram do projeto, todos assinaram contratos com as agroindústrias. Segundo relato dos produtores, os documentos asseguram-lhe ao menos uma margem de lucro em relação aos gastos que tiveram, sendo uma garantia para que não fiquem à mercê dos intermediários. Estes, por muitos anos, foram um problema para a agricultura em geral, não apenas para a tomaticultura, pois, aproveitando-se da falta de conhecimento e de informações que os produtores tinham sobre a cadeia de produção em que estavam inseridos, pagavam preços por sua produção que, às vezes, não cobriam os gastos.

Teoria e Evidência Econômica - Ano 19, n. 40, p. 153-168, jan./jun. 2013 
Os contratos firmados entre agroindústrias e produtores ajudam ambas as partes a defenderem-se dos intermediários. Aos produtores cabe entregar todo o montante que está acordado no contrato, sem que haja concessões; já a indústria recebe apenas o montante que está no contrato, não comprando tomates, nos termos utilizados, "frios", isto é, de procedência desconhecida. Com isso, a indústria pode rastrear os tomates que recebe, e os produtores não precisam se esforçar para vender sua produção.

Os contratos garantem, também, margem de segurança em relação à qualidade básica que os frutos devem apresentar. O plantio e os tratos culturais referem-se à obrigação do produtor, de modo que o quesito relativo aos defensivos agrícolas é regulamentado pelos contratos, cujas cláusulas, para serem mantidas, demandam o cumprimento de uma série de fatores por parte do tomaticultor:

- não plantar em áreas onde há sucessão da cultura de tomate e que apresentam pré-disposição a doenças;

- não plantar em áreas onde foram utilizados inseticidas muito agressivos, que não são recomendados para a cultura do tomate;

- fazer rotação de cultura;

- caso feita uma aplicação de defensivo, justificada por extrema necessidade, no período próximo ao da colheita, o produtor deve esperar o período de carência mínimo para proceder à colheita.

Essas são algumas cláusulas determinadas pelas agroindústrias para que haja o mínimo de segurança em relação aos frutos que estão adquirindo. Diante disso, o produtor deve ter um controle rigoroso, pois a quebra de uma dessas cláusulas resulta em multa por parte da agroindústria, ou, mesmo, em quebra de contrato.

\section{Considerações finais}

Os resultados obtidos, postos à análise descritiva e às análises estatísticas, possibilitaram concluir que a maior parte dos tomaticultores estudados no trabalho, os quais lidam diretamente com aplicação de defensivos nos tomatais da região em pauta, não se preocupa com sua saúde. $O$ fato agrava-se ainda mais diante da falta de assistência técnica qualificada para orientá-los quanto à condução da cultura do tomate.

A carência de um controle preventivo com os restos de safra e frutos de tomate atacados levou a um aumento de pragas e doenças na região e, consequentemente, ao uso indiscriminado de defensivos agrícolas, determinando que se elevassem os custos de produção. Embora a variável gastos com defensivos agrícolas tenha 
apresentado um nível de significância baixo, evidenciou-se que mesmo os menores gastos com defensivos agrícolas reduzem o lucro que os produtores poderiam ter se fizessem o uso consciente desses produtos. As variáveis gastos com fertilizantes, mão de obra e outros gastos não apresentaram efeitos estatisticamente significativos na renda líquida, mas a utilização além do ótimo de produção de fertilizantes e mão de obra pode causar a queda no lucro dos produtores.

A cultura do tomate industrial mostrou-se rentável, porém de alto risco. Já os contratos representaram uma evolução visível na segurança dos produtores em relação aos preços pagos e à margem de lucro que podem calcular sobre a safra que irão plantar. Assim, com tal respaldo, os produtores podem organizar melhor sua produção e seus gastos. Por parte das agroindústrias, os contratos mostraram-se interessantes, na medida em que suas cláusulas garantem a compra de frutos de maior qualidade, evitando que tomates clandestinos sejam adquiridos durante os ciclos de produção.

Seria interessante aos produtores a criação de uma cooperativa, com vistas a obterem maiores vantagens em relação à agroindústria na negociação dos contratos, reduzindo gastos na compra de insumos e, assim, viabilizando a aquisição de maiores quantidades, mediante descontos. 


\title{
Characterization of industrial production of tomato at Morrinhos/GO: the defensives use of the advantage of contracts
}

\begin{abstract}
The present study sought to characterize the tomato growers in the region of the municipality of Morrinhos/GO, production costs, as highlighting the impact of the use of pesticides in the production cost and profitaility. It also sought to examine the importance of contracts for agricultural producers and processing industries of tomato production in the municipality of Morrinhos. Data were subjected to analysis proposed by Samuelson and Nordhaus (1993) for which it was made the calculation of revenue. The t test Student was used to compare the means of production costs and net producers in the two groups, large and small producers. Subsequently, we used the model proposed by Hoffmann net (1998), which is based on an algorithm to determine the net revenue of certain business. It was noted that farmers abuse the use of pesticides, increasing production costs and that contracts have advantages in defese of the producer, and ensuring profits for the industry, ensurin higher quality products.
\end{abstract}

Keywords: Morrinhos/GO. Contracts. Pesticides. Tomato.

\section{Caracterización de la producción industrial de tomate en Morrinhos/GO: el uso de plaquicidas de la ventaja de los contratos}

\section{Resumen}

El presente estúdio busco caracterizar los productores de tomate em lá región del município de Morrinhos/GO, las tecnologias empleadas costos de producción y lãs características del mercado del comprador, así como destacar el impacto del uso de plaquicidas em los costos de producción y la rentabilidad. Tambíén trató de examinar la importancia de los contratos a los productores agrícolas y las industrias de transformación de La producción de tomate em el município de Morrinhos. Los datos se sometieron a análisis propuesto por Samuelson y Nordhaus (1993) para los que se hace el cálculo de los ingresos. El Student prueba t se utilizó para comparar las medias de los costos de producción y de los productores netos en los dos grupos, los productores grandes y pequeños. Posteriormente, se utilizó el modelo propuesto por Hoffmann neta (1998), que se basa en un algoritmo para determinar los ingresos netos de ciertos negocios. Se observó que los agricultores abusan del uso de plaquicidas, causando el aumento de los costos de producción y los contratos que tienen ventajas em defensa del productor, y asegurar los benefícios de La industria, ló que garantiza productos de alta calidad

Palabras clave: Morrinhos/GO. Contratos. Plaquicidas. Tomate. 


\section{Nota}

1 Samuelson e Nordhaus propuseram a classificação da produção em três fatores de produção: recursos naturais, recursos humanos e bens de capital. Nessa proposta, os bens de capital duráveis podem ser negociados em mercados competitivos, como ocorre com hectares de terra produzidos e horas de trabalho, mediante pagamento de aluguel por seu uso temporário. Para que, a conceito fundamental, se concretize, tem que haver a taxa de retorno sobre o capital.

\section{Referências}

ANDREI, O. Guia prático de produtos fitossanitários para uso agrícola. 5. ed. São Paulo: Organização Andrei, 1996.

BARROS, A. J. S.; LEHFELD, N. A. S. Fundamentos de metodologia científica: um guia para a iniciação científica. São Paulo: Makron Books, 2000.

BEULUKE, R.; BERTÓ, D. J. Metodologia de custo no agronegócio: um estudo de caso na cultura da soja (convencional e transgênica). Revista do conselho regional de contabilidade do Rio Grande do Sul, Porto Alegre, p. 27-47, dez, 2004.

BRITO, L.; CASTRO, S. D. Expansão da produção de tomate industrial no Brasil e em Goiás. Boletim da Seplan. 2010. Disponível em: <www.seplan.go.gov.br>. Acesso em: 01 jan. 2012.

CALDERÓN, L. E. V.; FERREIRA, A. C. M. Estudo da economia de escala na piscicultura em tanque-rede, no Estado de São Paulo. Informações Econômicas, São Paulo, v. 34, n. 1, p. 7-17, jan. 2004.

CARVALHO, J. F.; PAGLIUCA, L. G. Tomate, um mercado que não para de crescer globalmente. Hortifruti Brasil, jun. 2007.

COASE, R. The nature of firm. In: WILLIAMSON, O.; WINTER, S. G. (Ed.). In the nature of the firm origins, evolution and development. New York: Oxford University Press, 1993.

DIAS, D. R. Coordenação contratual na agroindústria do tomate. Cadernos de Debate, v. VII, 1999.

DIAS, D. R. Relações contratuais na agroindústria em Goiás: o caso dos produtores de tomate. Texto para discussão. Disponível em: <www.sober.org.br/pdf/texto_para_discussao >. Acesso em: 30 nov. 2011.

EMPRESA BRASILEIRA DE PESQUISA AGROPECUÁRIA (Embrapa). Centro de Pesquisa Agropecuária em Hortaliças (CNPH). Cultivo do tomate (Lycopersicon esculentum Mill). Brasília, DF, 1994. 22p. (Documento n. 11).

. Tomate: informações e manejos. Disponível em: <http://www.cnph.embrapa.br/ paginas/dicas_ao_consumidor/tomate.htm>. Acesso em: $12 \mathrm{dez} .2011$.

Economia do tomate. Disponível em: <http://www.cnph.embrapa.br/paginas/ dicas_ao_consumidor/tomate.htm>. Acesso em: 01 jan. 2012.

. Centro de Pesquisa Agropecuária do Trópico Semiárido (Petrolina, PE). Recomendações técnicas para o cultivo de tomate industrial em condições irrigadas. Petrolina: Embrapa-CPATSA/ Fundestone, 1994. 52p. 
FAO. Production Yearbook, Roma, v. 63, 2010.

FARINA, E. M. M. Q.; AZEVEDO, P. F.; SAES, M. S. M. Competitividade: mercado, estado e organizações. São Paulo: Singular, 1997.

FIANI, R. A teoria dos custos de transação. In: KUPPER, D.; HASENCLEVER, L. Economia industrial. Rio de Janeiro: Campus, 2002. p. 276-306.

GIL, A. C. Técnicas de pesquisas em economia e elaboração de monografias. 3. ed. São Paulo: Atlas, 2000.

HOFFMAN, R. Correlação e regressão. In: Estatística para economistas. 3. ed. São Paulo: Pioneiras, 1998.

INSTITUTO BRASILEIRO DE GEOGRAFIA E ESTATÍSTICA (IBGE). Séries temporais para a agricultura. Sistema IBGE de Recuperação Automática - (Sidra). 2013. Disponível em: <http:// www.sidra.ibge.gov.br>. Acesso em: 31 jan. 2013.

JIAMBALVA, J. Contabilidade gerencial. Rio de Janeiro: LTC, 2002.

MARCONI, M. A.; LAKATOS, E. M. Técnicas de pesquisa: planejamento e execução de pesquisas, amostragens e técnicas de pesquisa, elaboração, análise e interpretação de dados. 4. ed. São Paulo: Atlas, 1999.

MARTIN, N. B. et al. Custos: sistema de custo de produção agrícola. Informações Econômicas, São Paulo, v. 29, n. 9, p. 97-122, set. 1994.

MELO, P. C. T.; VILELA, N. J. Desempenho da cadeia agroindustrial brasileira do tomate na década de 90. Revista Horticultura Brasileira, Brasília, v. 22, n. 1, p. 154-160, jan./mar. 2004.

MIELE, M. Contratos, especialização, escala de produção e potencial poluidor na suinocultura de Santa Catarina. 2006. 286 f. Tese (Doutorado) - Programa de Pós-Graduação em Agronegócios, Universidade Federal do Rio Grande do Sul - UFRGS, Porto Alegre, 2006.

NOGUEIRA, A. C. L. Custos de transação e arranjos institucionais alternativos: uma análise da avicultura de corte no Estado de São Paulo. 2003. 153 f. ????? (?????) - Universidade de São Paulo, Faculdade de Economia, Administração e Contabilidade - USP, São Paulo, 2003.

PEREIRA, S. M. et al. Análise de contratos na suinocultura sob a óptica da Nova Economia Institucional. In: CONGRESSO DA SOCIEDADE BRASILEIRA DE ECONOMIA E SOCIOLOGIA RURAL, 46, 2008, Rio Branco. Anais... Brasília: Sober, 2008. Disponível em: <http://www.sober. org.br/palestra/9/534.pdf>. Acesso em: 28 jan. 2013.

ROCHA JÚNIOR, W. F. R. et al. Avaliação de contratos: uma abordagem utilizando a Análise Fatorial de Correspondência. Revista de Economia e Sociologia Rural, Piracicaba, v. 46, n. 2, p. $455-480$, abr./jun. 2008.

SAMUELSON, A. P.; NORDHAUS, D. W. Análise de custos. In: Economia. 18. ed. Portugal: McGraw-Hill, 1993. p. 139-181.

SANTOS, M. M.; NORONHA, J. F. Diagnóstico da cultura do tomate de mesa no município de Goianápolis, estado de Goiás, Brasil. Pesquisa Agropecuária Tropical, v. 31, n. 1, 2001.

SILVA, J. B. C.; GIORDANO, L. B. Produção mundial e nacional. In: SILVA, J. B. C.; GIORDANO, L. B. Tomate para processamento industrial. Brasília: Embrapa Comunicação para Transferência de Tecnologia/Embrapa Hortaliças, 2000. 
SRAFFA, P. Relações entre custo e quantidade produzida. Trad. de José Walter Martinez. São Paulo: Hucitec, 1989. (Série Economia e Planejamento).

VICENTE, M. C. M. et al. Perfil do aplicador de agrotóxicos na agricultura paulista. Informações Econômicas, v. 28, n. 11, 1998.

ZYLBERSZTAJN, D. Papel dos contratos na coordenação agroindustrial: um olhar além dos mercados. Aula Magna de abertura do XLIII Congresso Brasileiro de Economia e Sociologia Rural, Ribeirão Preto - SP, 2005.

ZYLBERSZTAJN, D.; SZTAJN, R. Direito e economia: análise econômica do direito e das organizações. Rio de Janeiro: Elsevier, 2005. 